\title{
Risk of Exposure to Marketed Milk with Antimicrobial Drug Residues in Ghana
}

\author{
K.G. Aning ${ }^{1}$, E.S. Donkor ${ }^{*}, 1,4$, A. Omore ${ }^{2}$, G.K. Nurah ${ }^{3}$, E.L.K. Osafo ${ }^{3}$ and S. Staal ${ }^{2}$ \\ ${ }^{I}$ Animal Research Institute, Council for Scientific and Industrial Research, Achimota, Ghana \\ ${ }^{2}$ International Livestock Research Institute, Nairobi, Kenya \\ ${ }^{3}$ Faculty of Agriculture, Kwame Nkrumah University of Science and Technology, Kumasi, Ghana \\ ${ }^{4}$ Department of Microbiology, University of Ghana Medical School, College of Health Sciences, Accra, Ghana
}

\begin{abstract}
The study was carried out to determine the extent to which antimicrobial drugs may be translocated into milk and the associated risk of exposure by consumers. A total of 394 milk samples were collected in the study sites in dry and wet seasons, and from different categories of milk market agents, including producers (farmers), processors, wholesalers (assemblers) and retailers. The milk samples were screened for antimicrobial drug residues using the Charm Aim-96 antimicrobial inhibition assay screening kit. Overall, 35.5\% (140/394) of the milk samples collected were contaminated with one or more of the antimicrobial drugs screened. This translates into an average risk of exposure every third time a consumer drinks locally produced milk. There was no significant difference in contamination levels between season and area of sampling. Among market agents, contamination levels ranged from $16.6 \%(9 / 54)$ for wholesalers or milk assemblers to $54.2 \%$ (13/24) for milk processors. There were no significant differences in prevalence proportions of drug residues in milk from different types of traders between and within locations.
\end{abstract}

\section{INTRODUCTION}

Dairying is a young and developing industry in Ghana that can potentially create many more employment and income-generating opportunities in rural and urban areas than is currently the case. Up to now, a large proportion of milk consumption is derived from imported milk products. This is partly because many consumers consider the locally produced milk to be generally of low quality or unsafe due to various documented and undocumented reasons. Documented health risks mainly relate to microbial hazards and poor quality of milk produced locally $[1,2]$. However, risks related to antimicrobial drugs remain largely unknown.

Various antimicrobial agents used in the treatment of animal diseases have been shown to occur in milk and other animal products used as food by humans. Although antimicrobial drugs are useful for treatment of human infections, their occurrence in milk causes adverse public health effects such as drug resistance and hypersensitivity that could be life threatening [3]. A significant proportion of humans are at risk. For example, about $3.4 \%$ of the human population is sensitive to sulfonamides [4], one of the antimicrobial agents screened in this study.

To protect the public against possible health risks caused by such hazards, regulations regarding veterinary use of drugs, including withholding periods after antimicrobial therapy, have been formulated. However, such regulations are not usually adhered to, especially in developing countries [5]. Consequently, undesirable exposure to antimicrobial drug residues tends to be higher in developing countries than

*Address correspondence to this author at the Department of Microbiology, University of Ghana Medical School, College of Health Sciences, Accra, Ghana; E-mail: ericsdon@hotmail.com elsewhere. This study was carried out to determine the occurrence of antimicrobial drug residues in marketed milk in Ghana and to estimate the exposure by milk consumers to the residues.

\section{MATERIALS AND METHODS}

\section{Study Area and Sampling}

The study was carried out at two sites namely, the periurban areas of Accra and Kumasi, the two cities in Ghana (Fig. 1). The areas were selected to represent a variation in consumer concentration, market access, and dairy production intensity. Accra, which has a higher population density, was chosen to represent high market access and relatively more intensive dairy production compared to Kumasi that has a lower population density, medium market access and more extensive dairy production systems around it.

The study was carried out in two steps. First, Participatory Rural Appraisals (PRAs) were conducted among consumers, marketing agents and producer-sellers at each study site at the beginning of the research to identify consumer preferences and practices, types of marketed dairy products, major marketing pathways, points and milk handling practices by market agents.

In the second step, the information obtained during the PRAs was used to construct a structured questionnaire and to select locations for field surveys in specific areas considered by key informants to have dairy marketing as an important activity. In and around both cities, data were collected in these locations by questionnaire from randomly selected milk traders during the dry (December 1999 - March 2000 in Kumasi area and March - June 2000 in Accra area) and wet (July - September 2000 in Kumasi area and July - October 2000 in Accra area) seasons. Respondents comprised different categories of market agents including producers (some of 


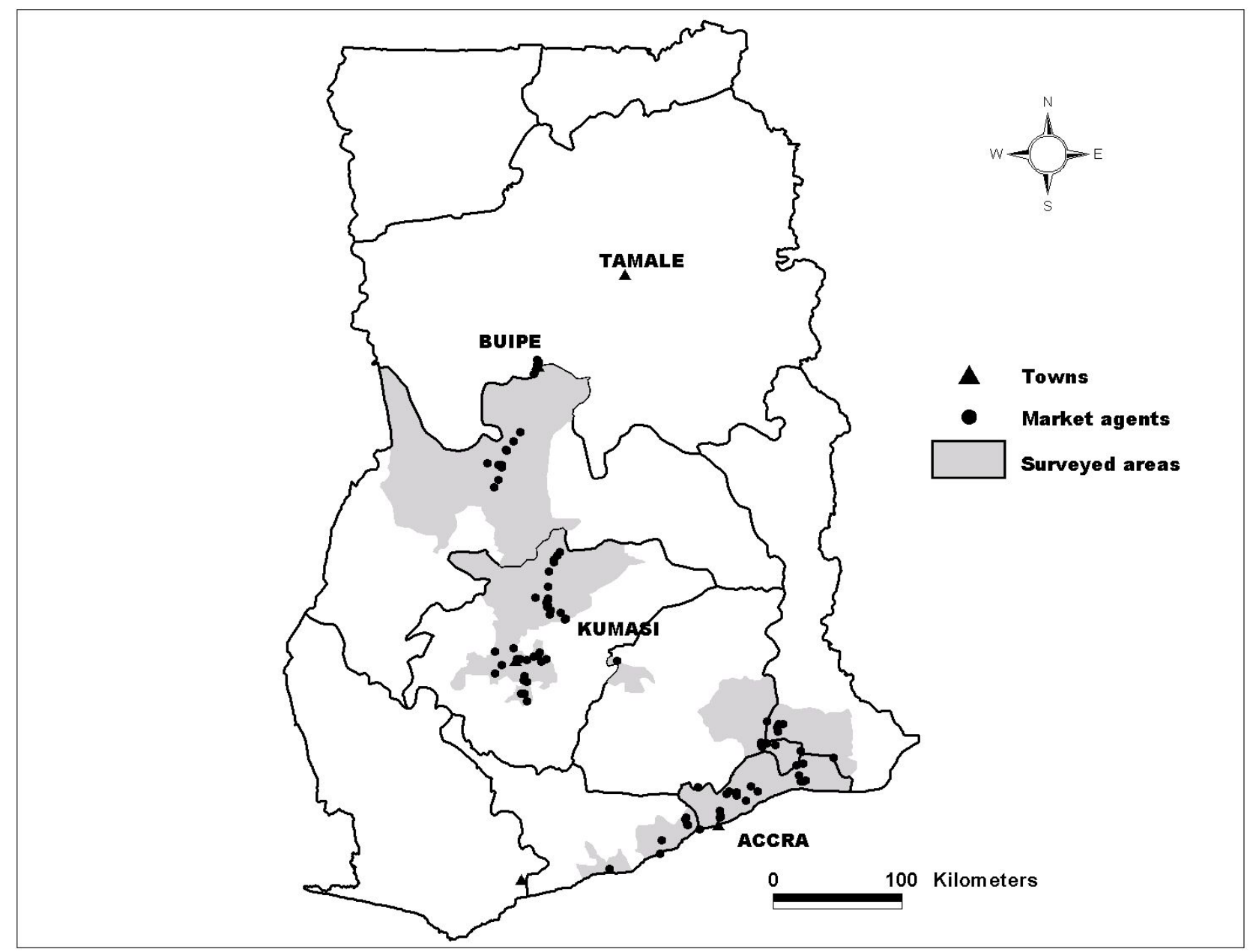

Fig. (1). Map of study sites in Ghana.

whom were herdsmen who own the milk but not the animals), processors, wholesalers or assemblers, and retailers. More than one sample was collected per respondent in 11 cases where product differences or handling warranted it.

The sampling of market agents varied by their location and type (Table 3). A total of 5 locations were sampled in Accra. In Kumasi area, market agents were sampled in 7 locations, including Buipe (294km north of Kumasi) that is also a source of milk for Kumasi market. All bulking centres (wholesalers or assemblers) were sampled. Smaller scale market agents (producer-sellers, processors and retailers) were identified through local informants and up to 30 of them sampled randomly at each selected location. Simultaneously with the structured interviews, samples of milk and dairy products were collected from each market agent interviewed. The milk samples were collected into sterile containers and transported on ice to the laboratory for analysis.

\section{Laboratory Detection of Antimicrobial Agents in Milk by Charm Aim Test}

The Charm Aim-96 anti-microbial inhibition assay screening kit (Charm Sciences Inc., USA) was used according to the manufacturer's recommendations. This test detects beta-lactams, tetracyclines, aminoglycosides, macrolides and sulphonamides at levels above maximum residue limits recommended by the European Union (Table 1).

Fifty $\mu 1$ of each sample were added to microtitre plate followed by $200 \mu \mathrm{l}$ of a mixture of Bacillus stearothermophilus spore tablet and lyophilised medium dissolved in 22 $\mathrm{ml}$ of deionised water. The plate was then sealed and secured tightly by screws and incubated for 3-4 hours. Positive and negative controls were included in the assay. The positive milk control consisted of antibiotic-free milk mixed with penicillin $\mathrm{G}(4 \mathrm{ppb})$ or sulfamethazine $(50 \mathrm{ppb})$ standard. To $50 \mu \mathrm{l}$ of the positive control, $200 \mu \mathrm{l}$ of bacterial spore and lyophilised media were added. The negative control consisted of $50 \mu 1$ of negative control tablet dissolved in distilled water and $200 \mu \mathrm{l}$ of the test bacteria and media dissolved in deionised water. Following incubations, the test results were read using colour contrasts and scored from 1-5 (negative $=1-3$ and positive $=4-5$ ).

\section{Data Analysis and Estimation of Risk of Exposure to An- timicrobial Residues}

Field survey and laboratory data were entered into MSExcel spreadsheet and analysed in Stata 6.0 (Strata Corporation, 702 University Drive East College Station, Texas) to describe: a) sources and volumes handled and b) prevalence proportions of samples with MRLs above recommended 
Table 1. Antimicrobial Residue Test Detection Ranges/Levels for CharmAIM-96 Test Kit, Their Maximum Residue Limits (MRLs) as Set by the European Union and Acceptable Daily Intake (ADI) Prescribed by the Codex Alimentarious Commission

\begin{tabular}{|c|c|c|c|c|c|}
\hline Gentamicin & $30-100$ & - & 100 & - & 20 \\
\hline Tylosin & 40 & - & 50 & - & - \\
\hline Chlortetracycline & - & $225-275$ & - & 300 & 30 \\
\hline Oxytretacycline & $150-300$ & $125-175$ & $100^{\mathrm{b}}$ & 300 & 30 \\
\hline Tetracycline & - & $50-70$ & - & 300 & 30 \\
\hline \multicolumn{6}{|l|}{$\beta$-lactams } \\
\hline Amoxicillin & - & 5.6 & - & 10 & - \\
\hline Penicillin G & $3-4$ & 3.6 & 4 & 5 & $30 \mu \mathrm{g} / \mathrm{day}$ \\
\hline
\end{tabular}

${ }^{\mathrm{a}}$ Total sulfa drugs; ${ }^{\mathrm{b}}$ Total tetracycline drugs.

Sources: Adapted from Charm Sciences Inc., USA and Codex Alimentarious Commission Website.

levels and therefore potentially harmful levels of antimicrobial drug residues as determined by the Charm AIM test kit. The latter was done by source, locations, and type of market agents for both wet and dry seasons. The Fisher's exact chisquare test was used to compare prevalence proportions for various cadres of market agents within and between locations. Where no samples with drug residues were detected, the probability of this being the case given the sample size was tested using the hypergeometric probability exact formula for a population prevalence proportion of drug residues of $5 \%$. The estimated prevalence levels and frequency of consumption were used to estimate the risk of exposure to milk with antimicrobial residues.

The relative risks for presence of drug residues between location, season and traders were also measured using ordinary logistic regression in SAS (SAS Version 8.02, SAS Institute, Cary, NC, USA).

\section{RESULTS}

\section{Milk Market Pathways}

Most of the traded milk (68 \%) in the study sites originated from own farms (Table 2) and retailed by the owners themselves. The next most common source was herdsmen, which accounted for $22 \%$ of all sales. The volume of milk traded in each of the pathways is also shown in Table $\mathbf{2}$. One in every two respondents (50 \%) was female.

\section{Estimates of Prevalence and Risk of Exposure to Antimi- crobial Drug Residues}

A total of 394 milk samples were collected and tested in both the dry (222 samples) and wet (166 samples) seasons (Table 3). Overall, $35.5 \%$ (140/346) of milk samples tested were contaminated with one or more of the five families of antimicrobial drug screened. Given the sample size, the $95 \%$ confidence limits around this prevalence ranges from 30.8 to $40.3 \%$. There were no significant differences or odds ratios

Table 2. Sources and Mean Volumes of Milk Traded by Various Types of Milk Traders in Ghana

\begin{tabular}{|c|c|c|c|c|c|c|c|c|c|}
\hline Trader & \multicolumn{7}{|c|}{ Source of Milk } & \multicolumn{2}{|c|}{ Volume and Range of Milk Handled (Lit./Month) } \\
\hline Producer-sellers & 0 & - & 2 & 1 & 235 & 0 & $238(62)$ & $660(75-3,000)$ & $349(13-1,800)$ \\
\hline Processor & 1 & 15 & 3 & 2 & 12 & 0 & $33(9)$ & $2,555(180-7,500)$ & $1,398(94-7,500)$ \\
\hline $\begin{array}{c}\text { Wholesaler } \\
\text { (assemblers) }\end{array}$ & 0 & 41 & 3 & 3 & 5 & 1 & $53(14)$ & 2,383 $(150-2,000)$ & $2448(300-9,600)$ \\
\hline Retailer & 0 & 28 & 6 & 16 & 7 & 2 & $59(15)$ & $2,578(300-30,150)$ & $262(2-945)$ \\
\hline Total (\%) & $1(0.3)$ & $84(22)$ & $14(4)$ & $22(6)$ & $259(68)$ & $3(1)$ & $383(100)$ & & \\
\hline
\end{tabular}


Table 3. Comparisons of Antimicrobial Residues Above Recommended Maximum Residue Limits as Determined by Charm AIM96 Test by Location and Cadre of Market Agents in Ghana

\begin{tabular}{|c|c|c|c|c|c|c|c|c|}
\hline Season & \multicolumn{2}{|c|}{ Dry } & \multirow[b]{2}{*}{$\begin{array}{c}\text { Prev. } \\
\%\end{array}$} & \multirow[b]{2}{*}{$\begin{array}{c}\text { Prob. } \\
\text { Exact } \chi^{2}\end{array}$} & \multicolumn{2}{|c|}{$\frac{\text { Wet }}{7-10 / 00}$} & \multirow[b]{2}{*}{ Prev. \% } & \multirow[b]{2}{*}{ Prob. Exact $\chi^{2}$} \\
\hline Sample category \& Location & $\begin{array}{l}\text { No. Tested } \\
(\mathbf{N})\end{array}$ & $\begin{array}{l}\text { No. Positive } \\
\text { (n) }\end{array}$ & & & $\begin{array}{l}\text { No. Tested } \\
(\mathbf{N})\end{array}$ & $\begin{array}{l}\text { No. Positive } \\
\text { (n) }\end{array}$ & & \\
\hline \multicolumn{9}{|l|}{ Market agents in Accra } \\
\hline Producer-sellers & 44 & 22 & 50.0 & & 47 & 19 & 40.4 & \\
\hline Wholesaler (assemblers) & 25 & 5 & 20.0 & & 19 & 3 & 15.8 & \\
\hline Retailer & 12 & 4 & 33.3 & & 4 & 1 & 25.0 & \\
\hline Overall & 84 & 32 & 38.1 & NS & 72 & 24 & 33.3 & NS \\
\hline Producer-sellers & 76 & 28 & 36.8 & & 60 & 34 & 56.7 & \\
\hline Processor & 8 & 5 & 62.5 & & 11 & 6 & 54.5 & \\
\hline Wholesaler (assemblers) & 5 & $0^{\mathrm{a}}$ & 0.0 & & 5 & 1 & 20.0 & \\
\hline Retailer & 55 & 6 & 10.9 & & 18 & 4 & 22.2 & \\
\hline Overall & 144 & 39 & 27.1 & NS & 94 & 45 & 47.9 & NS \\
\hline Overall (all mkt agents) & 228 & 71 & 31.1 & NS & 166 & 69 & 41.6 & NS \\
\hline
\end{tabular}

Overall prevalence $=35.5 \%$.

Key: NS = Not significant at $5 \%$.

'This sample probability remains ' 0 ' if population drug residue prevalence is $5 \%$.

greater than 1.5 in the proportion of samples testing positive by location, season and market agent. However, samples from milk assemblers had consistently lower proportions ( $\leq$ $20 \%)$ testing positive.

The average prevalence of $35.5 \%$ indicates that consumers of locally produced milk are exposed to marketed milk samples with unacceptable concentrations of antimicrobial residues approximately every third time marketed milk is consumed. At such a high prevalence estimate, inference from the information in Table $\mathbf{1}$ shows that the probability of surpassing the acceptable daily intake (ADI) for the various drugs is high, depending on the frequency of consumption, quantities consumed and concentration of the residues in milk - which this study did not quantify. The highest risk of ingesting residues above the ADI levels prescribed by the Codex Alimentarius Commission was deemed to be for penicillin G-type or $\beta$-lactam antibiotics due to their low ADI of only $30 \mu \mathrm{g} /$ day and the high frequency of usage of these antibiotics locally, especially in the treatment of mastitis.

\section{DISCUSSION}

This is the first time a widespread assessment of drug residues present in marketed milk of this nature has been carried out in Ghana. The overall prevalence of approximately one in three is rather high, and indicates that there is a problem in the use of such drugs at the farm and/or along the milk marketing channels in the country. Similar studies in Kenya $[6,7,8]$ have shown that the prevalence proportion is considerable lower at $9-16 \%$. However, the risk of exposure or exceeding the ADI in Ghana may be lower given the very low per-capita annual consumption of milk of only $5 \mathrm{~kg}$ Liquid Milk Equivalent (LME) per person, a large proportion of which comprises imported dairy products that are expected to have lower levels of contamination, as compared to Kenya's per-capita annual milk consumption of $85 \mathrm{~kg}$ LME or over $100 \mathrm{~kg}$ LME per-capita annual milk consumption in many western countries.

It was observed in this study that milk market agents, especially bulkers, pooled milk from different sources. This practice could lead to gross contamination of milk with antimicrobial drugs. On the other hand, the relatively low level of contamination $(\leq 20 \%)$ observed in groups of samples collected from this source, though associated more with pooling of milk, could probably be due to the dilution effect of milk bulking. The extensive bulking from multiple sources associated with milk retailers may have reduced the concentration of antimicrobial drugs to below threshold levels that could be detected by the test employed.

Seasonality and area differences did not influence the prevalence levels significantly. This indicates that nonobservance of withdrawal requirements following drug therapy - the main factor considered to underlie the presence of the residues - may be unrelated to variations in these factors. The high prevalence proportions that were observed call for an urgent need for a greater level of awareness among farmers regarding withdrawal requirements following antimicrobial therapy. 
It is important to note that unlike health risks from zoonotic pathogens that may contaminate milk, antimicrobial agents in milk cannot be eliminated by heat treatment. It is also important to note that the high prevalence levels of milk contamination with antimicrobial agents can adversely affect starter culture growth and acid production during milk processing, thus permitting pathogens such as Salmonella spp. and Staphylococcus spp to grow [9].

This study has exposed a potentially serious public health problem for consumers of locally produced milk in Ghana. It is conceivable that repeated exposure over long periods to such frequency levels of contamination of milk may lead to mass antimicrobial resistance within communities [3], thus leading to the need to resort to more expensive drugs that a poor country such as Ghana can ill afford.

Two recommendations to begin to address this problem are: a) creation of more awareness among policy makers, and of the potential interventions, b) testing for the residues at milk bulking centres and c) further research to more clearly define the problem and how it can be addressed, especially at the farm level where non-compliance regarding withdrawal times following drug therapy is considered to be major cause. Socio-economic analysis of non-compliance would be required to understand the potential incentives that would lead to behavioural change among farmers.

\section{ACKNOWLEDGEMENTS}

The paper is an output of a research and development project funded by UK department for International Devel- opment (DFID) for the benefit of developing countries. The technical support provided by F. K. Kwarteng, P.W.K. Nartey, S. Ogbete and C. Arthur are gratefully acknowledged.

\section{REFERENCES}

[1] Abraham CA, Laryea AM. Preliminary investigation of the bacteriology of raw milk produced on the Accra plains. Ghana Med J 1968; 7: 100-103.

[2] Ayebo D, Assoku RKG, Oppong ENW. A study of the bacteriology of raw milk produced on the Accra Plains of Ghana. Ghana J Sci 1976; 16: 9-18.

[3] Oslon JC, Sanders AC. Penicillin in milk and milk products. Some regulatory and public health considerations. J Milk Food Technol 1975; 38: 630-633.

[4] Bigby M, Jick S, Arndt K. Drug-induced cutaneous lesion reactions. A report from the Boston Collaborative Drug Surveillance Program on 15,438 consecutive inpatients $(1975$ - 1982). JAMA 1986; 256: 3358-3363.

[5] FAO/WHO. Antibiotics. 3rd Milk Hygiene Report. Rome, Italy: FAO; 1970; pp. 56-58.

[6] Shitandi A. Risk factors and control strategies for antibiotic residues in milk at farm level in Kenya. [Ph.D. thesis on the internet]. Sweden: Uppsala University; 2004 [cited May 2006]. Available from http://www.dissepsilon.slu.se/00000554/01/Agraria458.pdf.

[7] Shitandi A, Sternesjö A. Research note: factors contributing to the occurrence of antimicrobial drug residues in Kenyan milk. J Food Protect 2004; 67(Pt 2): 399-402.

[8] Kang'ethe EK, Aboge GO, Arimi SM, Kanja LW, Omore AO, McDermott JJ. Investigation of risk of consuming marketed milk with antimicrobial residues in Kenya. Food Control 2005; 16 (Pt 4): 349-355.

[9] Marth EH, Ellickson BE. Problems created by the presence of antibiotics in milk and milk products- A review. J Milk Food Technol 1959; 22: 266-272. 